\title{
FORMACCÃO INICIAL E CONTINUADA DE PROFESSORES: DAS LICENCIATURAS À CONSTITUICÃO DE PEQUENOS GRUPOS DE PESQUISAS COMO ASSOCIAÇÕES LIVRES
}

\author{
Nataly Carvalho Lopes* \\ Universidade Federal de São Carlos (UFSCar), São Carlos - SP, Brasil \\ Washington Luiz Pacheco de Carvalho** \\ Universidade Estadual Paulista (Unesp), Bauru - SP, Brasil
}

RESUMO: Buscamos desenvolver aspectos de pesquisa que se debruçou sobre o acompanhamento de um grupo de professores no que denominamos Pequenos Grupos de Pesquisa (PGP) em escolas públicas de educação básica. Esse acompanhamento propiciou elementos que foram interpretados de acordo com a teoria da ação comunicativa, o que possibilitou a compreensão de um modelo de formação. O trabalho foi orientado de acordo com a pesquisa participante, cuja potencialidade se configurou no processo colaborativo de interação universidade-escola, que propiciou a formação e transformações em ambas as esferas. Dessa junção, resultaram relações entre os agentes da universidade e da escola que foram homogêneas. Por fim, pudemos inferir que os processos de interação que se propõem formativos e investigativos podem passar por momentos de problematização, ação comunicativa e consenso, para que a universidade se aproxime dos ideais de igualdade para com os professores da educação básica.

Palavras-chave: Ação comunicativa. Pequenos Grupos de Pesquisa (PGP). Pesquisa participante.

\section{INITIAL AND CONTINUED TEACHER TRAINING: FROM LICENSEES TO THE CONSTITUTION OF SMALL RESEARCH GROUPS AS FREE ASSOCIATIONS}

ABSTRACT: We sought to develop aspects of the research that focused on the monitoring of a group of teachers in what we called Small Research Groups (PGP) in public high schools. This accompaniment provided elements that were interpreted according to the communicative action theory, which made possible the understanding of a teacher training model. The work was oriented

"Doutora em Educação em Ciências pela Universidade Estadual Paulista (Unesp). Docente Pesquisadora na Universidade Federal de São Carlos campus Araras e do Programa de Pós-Graduação em Educação para a Ciência da mesma universidade. E-mail: < natalylopes@cca.ufscar.br > .

"Doutor em Educação pela Universidade de Campinas (Unicamp). Docente Pesquisador da Universidade Estadual Paulista campus llha Solteira e do Programa de Pós-Graduação em Educação para a Ciência, Unesp campus Bauru. E-mail: < wlpcarvalho@gmail.com>. 
according to the participant research, whose potentiality of this research modality was configured in the collaborative process of university-school interaction, that provided the formation and the transformations in both spheres. From this junction, relations between the university and the school agents were homogeneous. Finally, we can infer that the processes of interaction that are proposed formative and investigative can go through moments of problematization, communicative action and consensus, so that the university approaches the ideals of equality with the teachers of basic education.

Keywords: Comunicative action. Small Research Groups (PGP). Participative research.

\section{INTRODUCุÃO}

A área que discute a formação de professores de ciências tem sido tema de intensos debates, por isso a demanda crescente de divulgação de ações e pesquisas que decaiam sobre o trabalho crítico de formação docente. Nesse sentido, dedicamo-nos a delinear um problema específico, sobre como um determinado curso de licenciatura contribuiu para que os professores formados nele buscassem por lugares de formação continuada. Tais espaços visavam a articular universidade e escola, os quais denominamos Pequenos Grupos de Pesquisa (PGP), e buscamos caracterizá-los com o conceito de associações livres, de Jürgen Habermas.

Procuramos partir de uma situação particular, aquela em que diversos ex-alunos da licenciatura em Física da Unesp, campus Ilha Solteira-SP, propuseram-se a continuar vinculados à universidade, de modo que iniciaram a proposição e a manutenção desses PGPs nas escolas públicas de educação básica onde trabalhavam. Essa situação nos levou a diversos questionamentos, tais como: quais os elementos que propiciaram esta vontade de continuar vinculados à universidade? Como estes PGP poderiam ser conduzidos de modo a serem espaços formativos $e$ associações livres? Assim, as discussões em torno dessas perguntas nos propiciaram a compreensão de aspectos relevantes para a formação inicial e continuada de professores. Principalmente, levando em consideração a importância da ação comunicativa em todos os processos de formação, a necessidade de que os professores sejam membros de associações livres, das nuances que tornam a parceria entre universidade e escola processo democrático, como as contribuições da pesquisa participante descritas neste trabalho, e, finalmente a busca por temas do mundo da vida, que possibilitam a existência das associações de professores.

Desse modo, o trabalho que desenvolvemos abrangia estes três pilares: a) sobre a compreensão de um determinado curso de licenciatura, nos contextos das pesquisas para a formação de 
professores de ciências; b) da importância da ação comunicativa e da constituição de associações livres, dois conceitos de Habermas e; c) da busca por temas do mundo da vida ou da investigação temática, que se aproximavam da escolha, da compreensão e do desenvolvimento de uma questão sociocientífica. Embora esse último tema seja negligenciado neste artigo, propomos uma busca por compreender as relações entre a formação inicial e continuada desses agentes que denominamos ex-alunos, e que influenciaram professores em suas escolas, professores pós-graduandos e professores universitários a formarem grupos. Assim, esperamos poder levantar mais discussões sobre experiências inovadoras e potenciais para que, efetivamente, possamos desenvolver programas longitudinais de formação de professores, e não somente abandoná-los à solidão profissional que se instala após a primeira graduação.

\section{DA FORMACִÃO INICIAL À FORMAC̣ÃO CONTINUADA DE PROFESSORES: DISCUSSÕES A PARTIR DA TEORIA CRÍTICA}

De acordo com as discussões propostas por Jürgen Habermas, é possível que delimitemos tanto um contexto problemático e em crise, quanto uma proposta para a formação de professores para a superação dos problemas que permeiam essa temática. Segundo Prestes (1996, p. 11), a reconhecida crise na educação reproduz a mesma crise gerada na modernidade e na racionalidade, "a tradição clássica do pensamento pedagógico estremece diante das incertezas humanas e vê-se sitiada pelos mais variados apelos decorrentes da especialização do saber e da complexificação da sociedade". Nesse contexto, as associações livres aparecem como uma possibilidade de ação efetiva de transformação da realidade escolar, a partir das reflexões e das análises que são possíveis mediante a interação entre professores, comunidade e universidade, como discutiremos mais adiante.

Essa teoria crítica nos leva a discutir a formação contínua dos professores para a situação oposta àquela que caracteriza o solipsismo do professor na escola. Isso, diante do argumento apresentado por Estrela (2010), de que o sofrimento dos professores está ligado a um contexto de solidão e, simultaneamente, aos sofrimentos ético e organizacional. Essa ideia está vinculada à de que "os professores são os únicos produtores das suas práticas, isolando-se das diferentes crises que atravessam o sistema escolar, ideia perturbadora das suas subjectividades" (ESTRELA, 2010, p. 32).

Dessa forma, compreendemos que muitos questionamentos podem ser suscitados diante dos problemas que rondam a educação 
no Brasil, entre eles, os que relacionam o processo de formação inicial e continuada de professores, que não pode ser definida em termos lineares, rasos e desarticulados. Diante da formação inicial, concordamos com a posição de Alves (2010, p. 27), que afirma que os cursos de licenciatura devem propiciar:

Que o aluno tenha condições de fazer escolhas, como por exemplo: de optar em dar ou não continuidade à sua formação acadêmica por meio da pesquisa; de continuar inserido em um grupo ou ater-se à individualidade apenas. É preciso oferecer-lhe a condição de escolha e de encaminhamento na vida profissional.

Essa discussão também foi realizada por Diniz-Pereira (1999, p. 118), ao propor "uma nova cultura institucional das licenciaturas", que "deve ser entendida como a capacidade de as universidades, especialmente as públicas, responderem, de maneira qualitativa, aos desafios propostos pela nova conjuntura política e socioeconômica brasileira". Essa nova cultura está diretamente relacionada à ideia de que os cursos de formação de professores se reformulem para que os professores sejam capazes de atuar como agentes transformadores do ensino básico no Brasil.

Para essa reformulação no pensamento e na ação de formar professores, podemos levar em consideração o que coloca Habermas (1989), de modo que não existe forma de vida sociocultural que não esteja, ao menos, implicitamente orientada para o prosseguimento do agir comunicativo com meios argumentativos. E é essa vontade de se comunicar que deve ser resgatada até mesmo naqueles cépticos, que se colocam como observadores ou que se opõem, a priori, à comunicação. Como os exemplos das instituições públicas que não se abrem ao diálogo e formulam currículos e propostas dogmáticas, sem a devida participação pública. Esses atores são os que mais estão sujeitados ao sistema, cuja necessidade de busca pelo agir comunicativo é ainda mais importante. Ao contrário disso, recentemente, pudemos assistir à construção colaborativa da nova Base Nacional Comum Curricular, mas cujas discussões foram suprimidas após as reviravoltas políticas do país, a partir de 2016.

Esse agir comunicativo está sempre situado no mundo da vida, que deve ser constituído sob as tradições culturais comuns e que coexistam com a sociedade. Todos os processos devem ser interpretados cooperativamente, os atos de fala devem ser transparentes e não se encerram até o entendimento e o consenso. Nesses termos, a sociedade como mundo da vida: a) supõe a autonomia dos sujeitos, b) independe da cultura, e c) pressupõe a transparência da comunicação.

Segundo essas definições, a escola pode ser pensada como o mundo da vida, na medida em que restabelece a possibilidade de comunicação entre seus agentes, em um espaço onde predomina a 
autonomia e a busca incessante por entendimentos. Esses elementos poderiam ser os primeiros passos para que os professores se lançassem nas atividades voltadas para a compreensão dos problemas relacionados às escolas e às esferas mais amplas, que influenciam as práticas escolares. Nesse sentido, a ação comunicativa:

Refere-se à interação de ao menos dois sujeitos capazes de linguagem e de ação que (já sejam com meios verbais ou com meios extraverbais) estabelecem uma relação interpessoal. Os atores buscam entender-se sobre uma situação de ação para poder assim coordenar de comum acordo seus planos de ação e com isso, suas ações. $\mathrm{O}$ conceito aqui central, é de interpretação, se refere primordialmente à negociação de definições da situação suscetíveis de consenso (HABERMAS, 1996, p. 124).

No campo da educação, a definição de ação comunicativa representa a possibilidade de compreender como os sujeitos agem nos mundos da vida e do sistema e como os diálogos podem ser voltados para que todos compreendam os temas relevantes e suas relações de interesse e poder. Além disso, podemos buscar, por meio do mundo da vida, consensos sobre a formação que se espera, assim como as metodologias e os conteúdos correspondentes.

Ainda em atenção aos conceitos que orientaram este trabalho, Chapani (2010, p. 27) define as esferas públicas habermasianas como "um conceito basilar da teoria social de Habermas", cujas principais características são "a universalidade e igualdade de participação, a racionalidade na busca de entendimento e a publicidade crítica". Para Habermas (1987), as esferas públicas funcionam institucionalmente, na esfera da opinião pública que é formada pela arte, pela imprensa e pelos meios de comunicação. Esses meios possibilitam a reprodução da cultura e a participação do público na integração social, mediada pela opinião pública. $\mathrm{O}$ agente dessa esfera "é o público enquanto portador da opinião crítica; a sua função crítica é que se refere à ‘publicidade' (publizitat) como, por exemplo, o caráter público dos debates jurídicos" (HABERMAS, 1984, p. 14).

Assim, as associações livres

subverteram de fato os limites do direito burguês de associação: a sua meta declarada é a transformação dos interesses privados de muitos indivíduos em um interesse público comum, a representação e demonstração do interesse da associação como sendo confiavelmente universal (HABERMAS, 1984, p. 234).

Por isso, a importância da formação dos grupos e da compreensão das questões de seu interesse com relação às mudanças, "nisso, as associações certamente não dispõem de amplo poder político apesar de seu caráter privado, mas exatamente por causa dele, sobretudo elas podem deixar-se controlar por ela" (HABERMAS, 1984, p. 234). 
Nesse sentido, os PGPs nas escolas funcionam em dois âmbitos: a) como associações livres, "são especializados na geração e propagação de convicções práticas, ou seja, em descobrir temas de relevância para o conjunto da sociedade, em contribuir com possíveis soluções para os problemas, em interpretar valores, produzir bons fundamentos, desqualificar outros" (HABERMAS, 1996 p. 110); e b) posicionados em discussões nas esferas públicas, interferem na política da escola, interagem com a pesquisa e no desenvolvimento de ações da academia, encontram brechas e possibilidades nos currículos provenientes do estado e nas ações das secretarias da educação e influenciam âmbitos como a sociedade local.

Para Kemmis (1993) o professor deve ser aquele responsável pela constituição de comunidades críticas, para o questionamento dos âmbitos político, cultural e social, "dentro e entre escolas, em organizações profissionais e, em alguma medida, dentro da administração educativa estatal. Também pode exercer certa influência na formação de comunidades críticas nas escolas locais e nas comunidades, grupos que impliquem a professores, pais, administradores escolares e outras pessoas interessadas" (KEMMIS, 1993, p. 22). Para Contreras (2002, p. 160) isso representa que

[o]s professores devem exercer um papel ativo, organizando-se junto com os pais e mães e outros setores da comunidade, com o objetivo de excluir do poder aquelas instituições e grupos políticos e econômicos que exercem uma influência excessiva e prejudicial sobre o currículo e a política escolar.

Assim, propomos que a profissionalização docente possa ser imersa em esferas de debate que incluam, primordialmente, os agentes mais diretos. Nesse caso, os agentes envolvidos são os próprios professores, que são "capazes de avaliar em plena consciência, o trabalho de seus pares" (CONTRERAS, 2002, p. 6). Esses agentes vivenciam e compartilham problemas, possibilidades, experiências, entre outros elementos que compõem o mundo da vida.

\section{O CONTEXTO DE FORMACุ̃̃O}

O grupo de pesquisa "Avaliação Formativa e formação continuada de professores", do qual participam os autores desta pesquisa, vem se desenvolvendo ao longo de 10 anos, com um histórico de investimento na análise e na proposição de situações de formação de professores com três aspectos em comum:

Amparo de um programa institucionalizado de formação; um convite para que os formandos invistam na formulação e desenvolvimento de um problema de 
pesquisa com apelo na sua experiência prévia; e manutenção de um grupo que se encontra semanalmente, para apresentação e a discussão dos trabalhos, em suas diferentes etapas (ORQUIZA-DE-CARVALHO et al. 2009, p. 2).

O histórico dessa proposta de formação começou com dois professores de Física, com interesses e envolvimento na pesquisa em ensino de ciências, que se inseriram na comunidade educacional da cidade desde 1998, anos antes da criação do curso de licenciatura em Física, na Unesp campus Ilha Solteira (ORQUIZA-DE-CARVALHO, 2005).

A partir deste ano, algumas fases podem ser descritas até o momento mais sistematizado que congrega o grupo de pesquisa em educação em ciências, que denominamos de grande grupo de pesquisa e que congrega ex-alunos, professores da universidade, professores das escolas de educação básica e pós-graduandos. A primeira fase foi caracterizada pelo esforço dos professores da IES em se inserir nos contextos das escolas públicas da cidade de Ilha Solteira, situação a qual possibilitou o desenvolvimento do conceito de pequenos grupos de pesquisa (PGPs). O segundo momento foi justamente a implantação do curso de licenciatura em Física, em 2002, com o desenvolvimento de monografias de conclusão de curso os primeiros Encontros de Prática de Ensino de Física (Enpefis) e, recentemente, o modelo do Enpefis que congrega o encontro de ex-alunos, o encontro dos pequenos grupos de pesquisa e de grandes grupos de pesquisa de outras IES, desde 2008.

Um aspecto importante desse curso de licenciatura em Física é a condução dos estágios supervisionados nas escolas, que propiciam a vivência docente e a busca por um problema de pesquisa, que os licenciandos perseguem até a elaboração da monografia de conclusão de curso. Esse processo está orientado para o desenvolvimento dos aspectos da subjetividade e da autoria dos futuros professores, que se tornam justamente as componentes que se relacionam com a autonomia, a criação e o agir crítico dos professores nas escolas quando imersos no processo de enfrentamento dos problemas escolares. Destacamos que essa proposta de formação inicial não é prática exclusiva do curso ao qual nos referimos, mas cujas bases teóricas e práticas têm sido exploradas contundentemente no campo da pesquisa em ensino de ciências.

Assim, o desenvolvimento, ainda na graduação, dessas pesquisas em educação em ciências é um dos elementos que contribuem para essa formação diferenciada dos ex-alunos, uma vez que refletem sobre os problemas educacionais, aproximam as discussões sociais da ciência, refletem sobre sua futura prática docente e são localizados no contexto educacional, sempre construindo a pesquisa coletivamente. Além desse fator, o processo de formação na graduação, com os estágios e a experiência prática como componente 
curricular nas disciplinas vão constituindo um agente particular, que tem como premissa a associação com os pares.

Assim, a história mais recente desses PGPs, que podemos descrever como uma segunda fase, teve início com a primeira reunião dos ex-alunos da licenciatura em Física, da Unesp campus Ilha Solteira, em dezembro de 2008. A compreensão sobre o que motivou esses agentes a se reunirem na universidade e, depois, nas escolas se refere a uma importante contribuição da teoria da ação comunicativa na formação inicial de professores - a vontade intrínseca dos agentes em formar grupos e se associar a outros professores, e que acarretou o tema de discussão deste trabalho, sobre a formação contínua de professores.

A partir de 2009, os PGPs estruturaram-se com a presença do ex-aluno, como coordenador, com os professores e os gestores da escola, um pós-graduando do grupo de pesquisa e um docente orientador da universidade. Os interesses de estudo desses PGPs estiveram ligados à formação de professores, questões sociocientíficas (QSC) e avaliação em larga escala.

Dessa forma, nossos registros foram iniciados em meados de 2011, já com o financiamento do projeto "Observatório da Educação" (Obeduc), da Coordenação de Aperfeiçoamento do Pessoal do Ensino Superior (Capes). Essa agência possibilitou a legitimação institucional dos PGPs, além do trânsito entre agentes das escolas e da universidade, de modo que pudemos acompanhar semanalmente o PGP situado na cidade de Arealva/SP. Esses grupos também puderam se encontrar em esferas públicas, como o Enpefis, e constituíam um polo de PGPs geograficamente próximos.

Nesse sentido, esse projeto é uma das vias de entrada da universidade na escola e vice-versa. Entretanto, a principal marca dessa relação é a existência de um professor pertencente ao grupo de exalunos. Esse agente, normalmente, transita com facilidade na escola e na universidade, por ser formado para se agregar com seus pares, em grupos.

Dessa forma, optamos por acompanhar o PGP da cidade de Arealva-SP, por diversas questões, como ser uma cidade próxima a Bauru, onde a pesquisadora reside, por se tratar de um dos primeiros PGPs a se constituir, por ter reuniões periódicas e por ter optado em discutir as questões sociocientíficas, tema de interesse da pesquisadora. Além disso, trata-se de um PGP que se articula bem com os demais e cujo coordenador esteve presente na I reunião de ex-alunos.

\section{O PAPEL DA PESQUISA PARTICIPANTE NA FORMAÇÃO DE PROFESSORES}

De acordo com Habermas (2012), o mundo da vida que não é intersubjetivamente partilhado é acrítico e não problematizado. 
Dessa forma, o envolvimento de profissionais de diferentes âmbitos educacionais poderia desencadear demandas por comunicação, devido aos elementos não partilhados, possibilitando a problematização. Por outro lado, os próprios professores das escolas, sem a participação dos pesquisadores universitários poderiam realizar pesquisas, considerando problemas da escola. Entretanto, a riqueza do trabalho entre universidade e escola se estabelece exatamente na construção de conhecimento abrangendo diferentes âmbitos educacionais, o que potencializa a ideia de formação por meio da ação comunicativa. Isso poderia representar o alargamento das questões específicas da sala de aula para contextos mais amplos, que permitissem observar nitidamente diversas imposições e possibilidades.

Para caracterizar devidamente o contexto que buscávamos, optamos por delinear a pesquisa qualitativa do tipo participante. Gajardo (1986, p. 45) delimita os processos da pesquisa participante nos seguintes aspectos: a) são baseados nas necessidades de grupos social e politicamente marginalizados; b) o ponto de partida, o objeto e a meta da pesquisa são o processo de aprendizagem dos que fazem parte da pesquisa; c) há a interação entre o pesquisador e o grupo que é interpretado; d) busca a comunicação horizontal entre os participantes, inclusive na orientação da pesquisa; e e) utiliza o diálogo como meio de comunicação mais importante no processo conjunto de estudo e coleta de informação. Julgamos esse último aspecto o mais marcante na pesquisa participante, já que esse tipo de pesquisa rompe com o "monopólio" do conhecimento, com a participação ativa dos envolvidos na compreensão da situação estudada.

Nesse contexto, a potencialidade da pesquisa participante está em que o processo colaborativo da interação universidade-escola propicia a formação e as transformações em ambas as esferas, pois "todos os participantes mudam, quer sejam mudanças em práticas, teorias ou expectativas em relação a si próprios e/ou aos outros, e essas mudanças não são iguais para todos, quer em qualidade, quer em intensidade" (MIZUKAMI, 2003, p. 210). Na visão de Mizukami (2003), a pesquisa compartilhada envolve planejamento, ensino, interação com os alunos e rotina burocrática compartilhados, não apenas a interação no sentido do diálogo, "ouvir para ver" do pesquisador.

Assim, para delimitar o assunto que propomos neste trabalho, elegemos a pesquisa participante como aquela que se aproxima dos propósitos da teoria da ação comunicativa, além de representar a nossa vontade em desenvolver processos de formação de professores intersubjetivamente. Para tanto, propomos dois momentos de interpretações: aquele em que os ex-alunos expressam 
a vontade de constituir grupos de formação e alguns momentos em que podemos analisar aspectos da ação comunicativa nesses grupos. Ademais, a pesquisa é participante e com os professores, uma vez que os participantes também desenvolveram papéis de pesquisadores e possuem seus trabalhos publicados em outras instâncias.

Para as interpretações que buscamos, escolhemos a análise de conteúdo (BARDIN, 1977) como o instrumento que compreende e relaciona os argumentos que desenvolveremos com a utilização das transcrições das falas dos agentes da pesquisa, em diversas situações de discurso. A partir dessa teoria, desenvolvemos eixos temáticos para as interpretações e as inferências possíveis a partir das falas dos participantes da pesquisa.

\section{MOTIVACִ̃̃ES QUE LEVARAM OS EX-ALUNOS DE VOLTA À UNIVERSIDADE}

Os diálogos que interpretamos nesta parte da pesquisa dizem respeito à transcrição da gravação em vídeo da primeira reunião dos exalunos do curso de licenciatura em Física da Unesp campus Ilha Solteira, no IV Enpefis, em 2008. A utilização desse instrumento foi importante, uma vez que o vídeo possibilita não somente o registro das vozes, mas também as expressões e as ações dos agentes envolvidos. Estavam presentes os professores da universidade, da escola, licenciandos de outros anos do curso e os ex-alunos que compuseram uma mesa-redonda.

Para a constituição da mesa-redonda, foram reunidos cinco ex-alunos: o ex-aluno $A$ professor mestre em ensino de ciências, que atualmente ${ }^{1}$ é doutorando em ensino de ciências e coordenador do PGP de Ribeirão Preto, o ex-aluno E que é professor mestre em Biofísica molecular e atualmente é professor da rede pública estadual, do ensino básico e do ensino superior particulares, a exaluna $N$ professora mestre em ensino de ciências, que atualmente é doutoranda e autora deste trabalho e dois professores da rede pública estadual de ensino, o ex-aluno $B$, já formado mestre em ensino de ciências e coordenador do PGP de Arealva e outro, o ex-aluno $A G$ que é mestrando na mesma área e coordenador do PGP de Birigui.

O contexto de comunicação propiciado pelo primeiro encontro de ex-alunos pode ser considerado como uma esfera pública, de acordo com as definições que utilizamos previamente, ao caracterizar os PGPs como associações livres e as esferas públicas como a reunião de diversas associações, em discussão pública que visa à ação. Assim, esse contexto acarretou a formulação de um eixo temático, no qual exploramos aspectos dos atos de falas dos 
ex-alunos que justificam a sua necessidade em restabelecer o diálogo com a universidade e a formação de grupos como ação fundamental para a formação continuada desses agentes.

Fiquei pensando sobre meu próprio processo formativo aqui na pós-graduação. Às vežes, penso que me falta a práxis efetiva, penso que estou longe da prática e muito inserida na reflexão. (Ex-aluna N)

Esta é uma visão que trago comigo desde o ano passado, quando ingressei no estado como professor e tive um choque de ideais, o que me angustiava, pensei até em mudar de profissão, mas no final do ano quando fui convidado pela professora "L" para falar como ex-aluno da profissão de professor e encontrei outros ex-alunos, os quais estavam encontrando praticamente os mesmos problemas, percebi que o caminho seria expor nossas dificuldades e tentar encontrar saidas para as mesmas. (Ex-aluno A)

Os atos de fala apresentados são de dois ex-alunos em situações profissionais diferentes. A primeira, como aluna de mestrado em educação para a ciência, expõe a preocupação com a falta de prática docente decorrente da inserção na pesquisa acadêmica. Essa situação é comum aos pesquisadores da área que se apoiam nas escolas para fazer pesquisas, mas não se inserem como membros dela, por isso, compreendem pouco sobre a organização formal ou informal das escolas. De acordo com essa reflexão, a pesquisa participante e a constituição de associações livres nas escolas são potenciais para que se efetive a imersão de professores da universidade e da escola em um processo intersubjetivo e horizontal de pesquisa e formação.

O segundo ex-aluno expôs a situação já caracterizada, de acordo com Hubermann (1992), sobre o choque de realidade que os professores iniciantes têm ao ingressar nas escolas. Esse autor relata como os jovens professores passam a se preocupar mais em sobreviver nas escolas do que com suas práticas. De acordo com a fala do ex-aluno A, a possibilidade do diálogo também é a possibilidade de enfrentar os problemas.

Assim, passamos a compreender como o curso de formação inicial é fundamental para inserir os agentes na ação comunicativa. Para tanto, a universidade pode estar aberta ao diálogo, além de fomentar a existência da comunicação nas escolas de forma que, "todo aquele que se engaja seriamente em uma argumentação, passou pelos processos de socialização, tem livre acesso à participação, há direitos iguais, confiança na veracidade dos participantes, vontade genuína, comprometimento" (ARAÚJO, 2004, s/p).

Em outra fala, é possível compreender como a união de professores em grupos corresponde ao fortalecimento das discussões sobre as tensões e as angústias da prática docente. Isso também corresponde à contramão da solidão profissional e à saída dos intelectuais de suas "torres de marfim" (GIROUX, 1997). 
É muito interessante a ideia de aproximar um formando e um ex-aluno atuante no ensino público el ou particular. Além da troca de experiências na elaboração dos $T C C 5^{2}$, ajudará aos futuros professores a adquirirem o que eu chamo de "pedagogia de sala de professor", que são os problemas que encontramos quando entramos em sala de aula e quais as atitudes que cada professor toma diante de tais problemas. (Ex-aluno E)

Eu vejo o grupo dos ex-alunos como um ambiente para expor nossas dificuldades e nossos objetivos, com o intuito de discutir e refletir com o grupo dos ex-alunos e todos os participantes do Enpefis. (Ex-aluno A)

A interação descrita nos atos de fala anteriores reflete os processos formativos que ocorrem durante a ação comunicativa. As trocas de experiências e a exposição das dificuldades possibilitam encontrar apoio nos diversos mecanismos da interação, como a pesquisa do professor, a constituição de referenciais teóricos, estudos coletivos, análises sobre as práticas, entre tantas outras opções que os professores podem encontrar ao se reunirem em associações. Essa situação condiz com a teoria de Habermas, na qual a ação comunicativa pode ser uma saída para a solidão profissional.

$\mathrm{Na}$ sequência do encontro, os ex-alunos iniciaram seus atos de fala com a narração de suas carreiras. Esse momento foi importante para constituir os contextos segundo os quais os ex-alunos produzem seus atos de fala. Após a explanação sobre suas carreiras, os ex-alunos apontaram as suas dificuldades e os aspectos que acarretaram as suas presenças no encontro. Nas falas a seguir, podemos observar a situação já relatada por Huberman (1992), sobre o choque de realidade que os professores iniciantes encontram na escola. Por outro lado, mesmo tratando-se de jovens professores, eles reconhecem o papel da sua formação inicial na prática docente e relataram como sempre procuraram interagir com os demais professores da escola.

Lembro que logo depois da minha primeira aula eu cheguei em casa desolado. Acho que tinha, acho que tudo aquilo que eu tinha acreditado desmoronou. Eu falei que en não queria mais aquilo, que eu nunca mais queria pisar em uma sala de aula, que... Então, diante de você não saber qual professor vocêe é, você se remete aos tempos que você era aluno, principalmente aluno dos cursos de física, e você passa a ensinar aquilo que você aprendeu enquanto você era aluno... Você chega, eu pedi lá, eles me deram uma caixinha, um gir. Nem livro eu tinha. E foi assim. Coordenador não veio falar comigo, direção. Teve o planejamento, mas é uma coisa também pra inglês ver, parece, é um espaço perdido. Assim como os HTPCs são. (Ex-aluno A)

Bom, vou ser breve como foi meu primeiro ano de trabalho. Primeiramente, cheguei super animado na escola. [...] E eu fui diminuindo meu ritmo de animação pra trabalhar, ai fui, que nem o Ex-aluno A falou, você acaba caindo no tradicional. Você é aquele professor tradicional, você não inventa mais. Daí eu cheguei em um ponto que eu tava indo lá passar a matéria na lousa, passava a matéria na lousa, acabava de passar, aluno copiava e explicava. Pensei, nossa minha aula tá horrivel, né, pra mim. Encostava na lousa 
e pensava "o que que eu to fazendo aqui, meu Deus". Essas pessoas, 40 pessoas aqui só esperando eu passar pra copiar. [...] É uma luta árdua mesmo, mas os momentos, por exemplo, de HTPC que nós temos as reuniões lá, só recados né. Não se discute nada, só recados, só cobranças. Ah, vai ter tal curso você tem que fazer. Online, não sei, você tem que fažer. Mas o que eu vejo é que alguém tem que ir lá, tem que ajudar, tem que por a mão na escola pública e mudar. Porque o que nós vemos não chega, não chega lá na escola pública. Pelo menos na que eu estou trabalhando não chega. (Ex-aluno AG)

A minha primeira angústia no estado foi a falta do ambiente universitário. Foi algo que eu conversei com o Ex-aluno $A G$, foi algo que eu conversei com o Ex-aluno $A$, que a gente manteve contato por MSN. Ninguém vê a escola como local de conbecimento. Ali é uma obrigação social que o aluno é obrigado a fazer. [...] E também não me foi mostrada ainda essa questão do conhecimento, porque a própria atitude do professor é cumprir um horário e ir embora. Então to colocando culpados. Se existe um culpado aqui é a visão de escola que existe na sociedade. Porque pra mim essa visão de escola que os alunos e professores têm é um reflexo da sociedade. (Ex-aluno B)

Mesmo assim o meu maior medo é estar no mestrado, e de repente me vir a pergunta, que de repente eu to olhando pro ensino, mas não to diretamente dentro dele. O dia que eu cheguei em Bauru e me deparei com uma escola central, a maior escola da cidade, ai me veio o choque. Pra mim foi um choque cultural, porque en sou do interior e sou de cidade pequena, estava acostumada com outra coisa. E aí eu acho que a gente acaba não tendo essa realidade toda, entendeu? Por mais que a gente esteja lá na prática, ainda é uma situação que não é geral. (Ex-aluna N)

Em todos os atos de fala, é possível reconhecer as angústias dos professores ex-alunos ao ingressarem na prática docente e, de certa forma, um pessimismo inicial. Essas angústias se referem ao mundo da vida nas escolas, que é possível conhecer apenas quando imersos naquele ambiente. Então, emergem as demandas, os problemas, os conflitos e os imperativos sistêmicos que limitam o agir dos jovens professores, mesmo que eles cheguem empenhados às escolas e queiram praticar o que aprenderam na formação inicial.

Ainda diante dessas críticas, os ex-alunos discursaram a respeito de como compreendem a importância da formação inicial em suas práticas pedagógicas. Os atos de fala a seguir remontam ao reconhecimento de elementos dessa formação inicial que possibilitaram aos ex-alunos transitar com mais facilidade pelo ambiente escolar e retomar o diálogo com a universidade.

Mas passado o choque, assim, eu vejo hoje em dia ainda que o ensino público ainda tem muitos problemas assim, problemas gritantes assim. Mas uma comparação que eu vejo assim, eu converso com alguns outros professores lá que são ingressantes, que vieram de outras escolas também. Uma diferença que eu vejo assim entre eu e eles é assim, que talvez valha a pena colocar aqui, é que assim o preparo que eu tive no curso de licenciatura de física me fez ver que por mais que existam problemas eu ainda não posso ficar de mãos atadas, né. Então, na medida que existe aqueles problemas, então, o que eu posso fazer diante daquilo. (Ex-aluno A) 
E uma coisa que sempre ficou muito comigo, que o curso deixon muito comigo me acompanhando era a importância de sempre tentar buscar informações sobre a área de educação. Ai aquelas coisas, né, você fica, você dá 60 aulas por semana, faz mestrado e ainda fica lendo de madrugada os livros lá. E eu acho que nós aqui, vocês principalmente professores aqui da universidade pública, eu sei que tem muitos trabalhos voltados pra escola pública. Mas compete a um aluno que tá saindo de um curso de licenciatura ter uma certa responsabilidade social com a realidade da escola pública. (Ex-aluno E)

Que você sente, e também tava na fala da ex-aluna $N$, você sente necessidade de estudar, você sente necessidade de um referencial teórico, você começa a fažer uma prática puramente prática. Você dá aula, dá aula, dá aula, dá aula, dá aula chega em um momento que você fala "poxa, eu estudei tanto! E onde que tá entrando agora essa questão?". Então esse é um ponto que eu me identifiquei com a fala dos colegas aqui. A gente tem que entrar pra, tem que ser um pouco de altruismo. Tem que ser altruista na minha opinião. Tem, você tem que chegar, imaginar soluções, buscar e não é só reclamar não. A gente... nesse ponto é praxis. (Ex-aluno B)

Assim como buscamos defender desde o início deste trabalho, o fortalecimento e o aprimoramento dos professores ocorrem na constituição de associações. Entretanto, fica expresso nas falas apresentadas, que a consciência da necessidade de se associar parte da formação inicial voltada para a ação comunicativa. O primeiro indício dessa afirmação é que a ex-aluna $N$ revela como descontentamento não praticar aquilo que aprenderam na universidade: "Aprende a estudar, a ir atrás. E eu acho que a lição do Enpefis é essa, é a questão de, você por mais anseios e angústias que você tenha depois, eu acredito que todo mundo que tá formando aqui na Ilha Solteira tá saindo com a pulga atrás da orelha".

Para compreender melhor a questão que levantamos sobre a necessidade de constituição de associações livres para a interação entre universidade e escola e para a formação de professores, elegemos a constituição de eixos temáticos, com a necessária ação comunicativa e elementos derivados desse agir. Assim, os atos de fala a seguir se referem aos momentos nos quais os ex-alunos expuseram a necessidade de se comunicar:

E com relação a uma parte da mobilização, eu acho interessante. A minha fuga é conversar com os colegas. Eu mantenho contato através da internet com o Ex-aluno $A$ e com o Ex-aluno AG. Então nossa fuga é trocar mensagem pelo MSN mesmo. E muitas vežes, a tentativa que eu venho no último encontro de estudo, o pessoal de Bauru foi também realmente procurar uma solução. Então eu vim pedir socorro. Então eu peço socorro para os colegas e quando dá eu venho pra universidade também. (Ex-aluno B)

Agora, com relação às discussões, eu discuto muito pouco com o Ex-aluno $A$ e, na escola, tem uma professora que no momento tá se doutorando que eu debato muito com ela, converso muito com ela. Ela tem uma idade próxima a mim assim, a gente fica lá debatendo, debatendo e vendo o que a gente pode fazer pra tentar melhorar a situação, mas falta muito esse contato com a universidade, né. (Ex-aluno E) 
A minha também não é diferente da dos outros aqui. Estamos no mesmo problema e é dificil mobilizar pra ter uma discussão, uma reflexão em cima do como melhorar, como faz̧er diferente. Então a gente acaba desabafando como? Trocando e-mail mesmo. Ó eu fir isso, que você acha, legal, né. O gerador... Você lembra? Mas ai o outro tá mal também, tá achando que não tá legal. Você manda e-mail pro cara, "não, vamos fazer diferente?". Tenta fazer isso, só isso. Agora reunião dos professores na minha escola falta muito isso, eu acho. Se tivesse isso poderia ser melhor o ensino lá. (Ex-aluno AG)

E é engraçado que a relação que eu tenho com ela (a outra professora de Física da escola) é, por melhor que seja a gente não consegue trabalhar junto. Ainda não conseguimos trabalhar juntos. Eu queria muito, ela quer muito, a gente gostaria de fazer as coisas juntos. [...] Talvez valeria a pena pensar um pouco mais porque que isso acontece, mas é uma coisa muito engraçada. Que você tem dois professores de física numa escola relativamente pequena, professores compromissados, competentes pra trabalhar juntos ali, mas que não conseguem trabalhar juntos. Não sei. (Ex-aluno A)

No eixo de análise no qual é expressa a vontade dos alunos em se comunicar, podemos encontrar o que Habermas chama de "vontade ontológica de entendimento". Nos atos de fala anteriores, podemos observar como os ex-alunos buscam se comunicar com os pares da escola e da universidade e como a inexistência dessa comunicação acarreta frustração. Ressaltamos ainda que os fatores que atravessam a comunicação estão relacionados às atividades burocráticas da escola, como o número elevado de aulas, os temas adversos dos ATPCs, a falta de tempo e de espaço para a interação entre os professores entre tantos outros, que caracterizam perfeitamente o que Habermas denominou de invasão sistêmica.

Diante do exposto, ressaltamos a importância da instauração desses espaços e de momentos propícios da comunicação docente, para os quais os projetos propostos pela universidade e por outras instituições possam ser direcionados. Essa ideia nos remete ao que cita Orquiza-de-Carvalho (2005), ao propor que p lugar dos projetos não pode ser somente na escola ou somente na universidade e que eles devem ser um dos meios da interlocução entre universidade e escola, uma vez que ambas as instituições visam à melhoria do ensino de ciências, mas precisam buscar consensos sobre os problemas a serem debatidos e as maneiras comuns de solucioná-los.

\section{INTERAC̣̃̃ES ENTRE UNIVERSIDADE E ESCOLA: A PROPOSTA DE FORMAÇÃO CONTINUADA NOS PGPS}

Nos atos de fala anteriores, compreendemos como há a necessidade de superarmos as pesquisas que apenas denunciam determinadas realidades, para desenvolvermos propostas que visem a alternativas para os problemas educacionais. Por isso, foi necessário 
compreender como a formação contínua poderia ocorrer após o início desses PGPs nas escolas, como proposta aos anseios expressos pelos ex-alunos. Nesse item, apresentamos breves interpretações da pesquisa que se desenvolveu em um PGP.

O PGP de Arealva/SP constituiu-se na "Escola Estadual Sebastião Inoc Assumpção", com a participação de um ex-aluno do curso de Física que também é mestrando ${ }^{4}$ (Ex-aluno B), dois pós-graduandos do mesmo programa, uma doutoranda (Pesquisadora) e um mestrando, cerca de seis professores da escola, com a colaboração e a comunicação com os gestores, um diretor e um coordenador pedagógico da escola.

Nos atos de falas subsequentes, podemos observar como os professores adquiriram essa compreensão de que os processos de formação não podem ser imediatos.

B, o interessante seria assim, se vocêpudesse conhecer um pouquinho das classes do primeiro $B$, dai a gente vai trabalhar com os dois seguimentos ou só com um. (Prof. AF)

Vocêfala... (Ex-aluno B)

Pra gente já colocar uma coisa concreta. (Prof. AF)

É, eu acho. Concordo com a AF, quanto antes, melhor. (Prof. HLZ)

É o seguinte, eu sempre tô pensando pra gente se estruturar bem é... a gente tem a proposta de fazer sequências didáticas e também de trabalhar com habilidades e competências, então pra gente fazer algo bem organizado com relação a isso, de trabalhar com competências, habilidades e envolver a realidade do aluno, mesmo que seja pra gente estudar esse semestre pra começar o ano que vem, porque a gente tem quatro anos de projeto, mas se a gente fizer uma coisa forte, estruturada, que mexa até com o PPP (Projeto Político Pedagógico) da escola a gente vai ter algo que vai acabar o projeto, mas que vai continuar. (Ex-aluno B)

A compreensão desse ex-aluno sobre o processo formativo é demonstrada em sua busca por conter as ações imediatas. Compreendemos essa situação como o inverso das ações instrumentalizadas do estado que envia, a cada momento, novas propostas para as escolas, sem preparar os professores e os gestores para a utilização ou crítica aos materiais. Ou seja, ações formativas são mais duradouras e concretas que propostas que são modificadas a cada nova administração estatal e têm um fim prematuro.

Embora também nos questionemos sobre como os agentes tomam consciência desse processo formativo, ele fica caracterizado pelos diversos conhecimentos que são mobilizados e construídos no grupo. Para o PGP de Arealva, os conhecimentos produzidos estão relacionados às pesquisas desenvolvidas pelos professores, sobre os desafios empregados na constituição de novos currículos, a partir das sequências didáticas e pela própria discussão coletiva da prática. 
Em continuidade a essas discussões, no sétimo encontro do PGP, enquanto os professores sugeriam uma ação supostamente imediatista para o trabalho com os alunos, o coordenador exaluno defendeu a necessidade de o grupo se preparar para as ações, compreendendo a complexidade do processo proposto. Essa ponte entre a proposta da universidade e a escola ocorre nesses momentos de inteligibilidade. $\mathrm{O}$ ator que caminhou nesse sentido, em quase todos os momentos foi o ex-aluno.

(Trecho inaudível) o que eu tava pensando, essa formação com o outro como uma forma
de tentar produzir esse questionamento (trecho inaudível) interdisciplinar, por quê??
Então, uma resposta particular, que pode ou não representar a opinião do grupo, mas é o
seguinte, as nossas atividades estão sendo uma... atividades interdisciplinares no momento
em que elas estão sendo construídas positivamente. As sequências didáticas apresentadas
pela professora $S$ e pela professora AF, são apresentadas no pequeno grupo de pesquisa
e os nossos estudos particulares, um sobre a participação em reuniões, estudo de artigos
que tratam do relacionamento entre agrotóxicos e suicídio, tudo isso soma-se algo de
conhecimento e as realidades vão sendo modificadas e adicionadas a essas informações de
todo o grupo. Então o professor $F$ traz o conhecimento, eu trago o conbecimento, aprofessora
AF, a professora $S$, a professora $H$. Todo mundo vai compartilhando e essa sequência
didática vai sendo transformada com o decorrer das reuniöes. (Ex-aluno B)

Nos atos de fala anteriores, o ex-aluno apresentou aspectos da intersubjetividade com o compartilhamento de conhecimentos, estudos e práticas dos agentes do PGP. Essas expressões representaram a ação comunicativa que possibilitou que os agentes pudessem se formar em conjunto. Como temos discutido, essa situação seria impossibilitada na solidão profissional desses professores. Portanto, reforçamos a potencialidade da formação de professores em associações livres que, neste caso, começou a ser caracterizada também pela liberdade de temas a serem discutidos.

Inseridos nos aspectos formativos, a comunicação oral dos trabalhos e das práticas pessoais representou um momento importante de formação representada pela experiência na argumentação. Essas situações foram representadas por diversos episódios nos quais os integrantes do grupo apresentaram seus trabalhos, para o próprio grupo e para agentes externos, como nas reuniões do grupo, nos Enpefis e nos congressos.

Expressar os entraves da ação comunicativa também é um elemento importante para o trabalho que desenvolvemos, pois temos indicado até o momento, como a interação universidade-escola, a formação de professores e o mundo da vida podem ser trabalhados de modo a constituir associações livres. Entretanto, devemos expressar como podem ocorrer situações que comprometem o mundo da vida e, assim, limitar as ações das associações. 
Dessa forma, Habermas infere sobre as invasões sistêmicas que corrompem o mundo da vida e impedem a ação comunicativa, mas precisamos entender como essas invasões sistêmicas ocorrem no microcosmo escolar. Dessa forma, um dos elementos que representou essa situação se refere à relutância que muitos agentes da escola têm em participar do PGP e das atividades propostas pelo grupo, como indicado nos atos de fala a seguir:

Mas isso é normal em todos os ambientes. Infelizmente, tem pessoas que reclamam, mas não querem mudar, eles não pensam, é uma ajuda que... (Prof. FL)

E é interessante o que tá acontecendo em Arealva com as QSC, porque o Ex-aluno B conseguiu um espaço no HTPC né, daí... (Mestrando)

Aconteceu meio torto, mas acabou sendo legal. (Ex-aluno B)

Ficou legal, porque tem essa coerência entre o discurso né tipo, o professor que vai lá, ele quebra o diálogo, mas no pessoal, ele quer que alguma coisa melhore, mas também não faz. nada pra melhorar, então, eu acho assim que quando o Ex-aluno B colocou esse episódio do HTPC, ai sim ele coloca essa categoria de vontade de formar grupos, quando o professor começa a perceber a incoerência do próprio discurso que ele apresenta, aquela vontade começa a aparecer né. Começa a desenvolver, por que eu to assim sabe? Eu acho que é assim que tem a maior importância do que tá acontecendo no HTPC (recentemente chamados ATPC), que é muito importante o que vai ficar... (Mestrando)

Porque os HTPCs são desperdiçados, é uma tortura estar ali, mas também não se fala nada, não se produz nada de bom é sempre uma cobrança, uma tristez̧a. (Professora PGP Birigui)

Porque os professores não estão ali porque querem, estão ali porque precisam ficar, tem que cumprir. (Ex-aluno B)

Textos impostos, sem sentido nenhum, não pode questionar. (Professora PGP Birigui)

Os atos de fala anteriores revelam uma situação comum nas atividades de trabalho pedagógico coletivo (ATPC) das escolas, que pontuam que esse tempo é usado apenas para comunicados ou discussões sobre a escola, que pouco contribui com a prática e com a formação de professores. Nesse sentido, durante um período, o PGP de Arealva assumiu esse horário e realizou algumas atividades sobre as QSCs com os demais professores da escola, que não participam do PGP. Entretanto, muitos desses professores foram relutantes quanto às atividades e procuraram $\mathrm{O}$ diretor da escola para proibir a atuação do PGP durante as ATPCs.

Com essa situação, os agentes do PGP começaram a questionar o porquê da não participação dos professores da escola no grupo, e o que o Ex-aluno B apontou foi que os professores participavam da ATPC por uma obrigação sistêmica e não por vontade. Mas a vontade é que deve ser o fator principal da participação no PGP.

Outro elemento importante sobre como a ação comunicativa fica impossibilitada é a burocratização da escola. A burocratização, 
de modo geral, já havia sido denunciada por Habermas como uma das expressões das invasões do sistema no mundo da vida. A seguir, podemos acompanhar atos de fala nos quais os professores descreveram a necessidade de informar a secretaria de educação acerca dos projetos da escola.

É... porque como a gente já tá acostumado a fazer projeto, você já vai, já coloca o tema, já coloca todos os textos que vai ler, todos os livros e o final, a avaliação do projeto né. Então, eu acho que eu tô naquele modelo tradicional né. (Professora AF)

Eu acho assim, eleger os livros e os textos que vai trabalhar é uma coisa que cabe ao professor mesmo né? Você pode até falar pro aluno ir fazer uma busca no Google, ele vai fazer, mas não tem o fim pedagógico que o professor quer. (Pesquisadora)

Acho que o problema maior é esse né professora AF, a gente não consegue levar sem identificar... vai dar problema, vai parecer que a gente levou pra passear. (Professor FL)

É uma coisa que não precisa ser resolvida hoje né, que o PGP tem que andar em paralelo com esse projeto né, mas a gente vai vendo essas coisas. (Pesquisadora)

É, eu acho assim, a gente pode conversar lá na escola né ex-aluno B, um dia a gente pode até vir aqui na secretaria conversar com a Sílvia, nós podemos combinar nós três e vir conversar com a Sílvia, com a supervisora. Dai se você tiver disponibilidade, você pode até ir com a gente lá. (Professora AF)

Conversar sobre a possibilidade de... (Ex-aluno B)

Então, de fundamentar, nós falaremos com o diretor sobre a possibilidade da criação de uma disciplina, mas dai seria projeto. (Professora AF)

$E$ aquela disciplina de apoio? (Pesquisadora)

$O D A C$, mas o $D A C$ já fechou. (Professora AF)

$E$ não abre de novo? (Pesquisadora)

É que o DAC é... já tem aquela oficina da abril. (Professora AF)

Nesses atos de fala, pudemos compreender como os projetos propostos nas escolas nem sempre deixam de acontecer por falta de vontade dos envolvidos ou por motivos locais das escolas. O que ocorreu, no caso do trabalho proposto com as QSCs no PGP de Arealva, foi a impossibilidade de que os temas fossem trabalhados com os alunos fora das aulas das disciplinas. Mesmo quando os professores se dispuseram a levar os alunos em esferas públicas, como a associação de agricultores da cidade, deveria haver uma autorização superior da secretaria regional de educação, ou os professores poderiam ser acusados de burlar as aulas na escola.

Dessa forma, consideramos esse aspecto um limitante das situações de discussões que gostaríamos de constituir como associações livres, principalmente pelas características principais desse agrupamento, de que deva ser desvinculada de instituições e que possa se autorregular. Isso pode ser percebido quando os professores relatam como os projetos 
devem se enquadrar em disciplinas próprias, como as disciplinas de apoio curricular (DAC) ou ser submetidos a análise no período correto.

Essa situação também pode ser retratada na padronização dos currículos e nas propostas pedagógicas que pouco têm a ver com o mundo da vida e agem segundo fins estratégicos. Isso reforça o argumento contrário às reformas e às propostas curriculares que partem dos governos, o que, para Habermas, também se configura como a perda da liberdade e da ação dos professores.

Por um lado, a maioria dos professores apresenta vontade de fazer parte do grupo, que é uma situação prevista por Habermas, com a vontade ontogênica de entendimento. Por outro lado, há elementos pessoais que acabam fazendo o papel de sistema e invadem o mundo da comunicação, mas que não devem ser deixados de lado ao se proporem projetos, pois sem articular as vontades e as disponibilidades das pessoas, os projetos acabam.

Diante dessas constantes interferências no funcionamento do PGP, a proposição, a discussão e a definição coletivas de normas foram necessárias para "proteger" os horários reservados para as conversas dos professores. Nesse sentido, o agir normativo apareceu nos atos de falas e se referiu aos mundos objetivo e social e esse modelo de ação

mune os atores não apenas de um "complexo cognitivo", mas também de um "complexo motivacional" que possibilita um comportamento adequado à norma. Além disso, o modelo de ação passa a vincular-se de um modelo de aprendizado da internalização de valores (HABERMAS, 2012, p. 172, grifos nossos).

Esse tipo de agir busca meios de manter a organização e as regularidades das reuniões do grupo, para que ele não seja a todo momento invadido pelas demandas sistêmicas e, com isso, distanciese dos elementos que o caracterizam como associação livre.

Esses aspectos puderam ser compreendidos até esta parte do trabalho graças ao olhar para as ações que ocorreram no PGP, tanto para caracterizá-lo como associação livre, como para compreendermos os elementos que atravessaram e impediram a ação comunicativa. Assim, ressaltamos a importância da experiência que realizamos, cujas ações normativas e comunicativas fortaleceram a associação livre e permitiram que as situações-limites da escola e das vidas dos professores fossem discutidas amplamente, para que então, pudessem propor projetos de intervenção nas aulas.

\section{CONSIDERACְ̃̃ES FINAIS}

O problema sobre a formação de professores foi proposto de acordo com o isolamento desses profissionais quando inseridos na escola, 
sobre como a realidade da escola pode chocar os professores iniciantes e sobre a inexpressividade desses atores nas propostas e na elaboração de leis e currículos educacionais. Para essas discussões, propomos a teoria da ação comunicativa com dois propósitos: analisar a situação do ponto de vista de uma teoria da sociedade e propor um meio de formação contínua de professores, de acordo com o agir comunicativo em associações livres.

$\mathrm{Na}$ primeira etapa das análises, apresentamos situações que contam a pré-história dos pequenos grupos de pesquisa nas escolas, sob a coordenação de ex-alunos. Tais situações possibilitaram a proposta de importantes temas para a compreensão de como foi iniciado o agir comunicativo dos pequenos grupos. A mesa-redonda composta pelos ex-alunos possibilitou a primeira visão da universidade para dentro das escolas antes da instauração desses PGPs, com o projeto Observatório da Educação.

Essas também são discussões importantes que apontam para a importância da formação inicial, pois esse momento do processo formativo dos ex-alunos foi o que constituiu essa tradição cultural e a vontade de se comunicar. Também houve a evidência de que a formação inicial não permitiu que esses ex-alunos ficassem apenas imersos na escola, sem questionar seus mecanismos. Além da vontade intrínseca dos seres humanos em se entender, como relata Habermas, a comunicação sempre foi a saída desses ex-alunos, desde a graduação, para compreender e modificar aspectos problemáticos que encontravam na escola e na prática docente.

Nesse sentido, a interação universidade-escola foi uma das primeiras formas de comunicação desses ex-alunos após saírem da licenciatura, mas essa interação teve que ocorrer também nas escolas, com a constituição dos PGPs. A compreensão sobre a pesquisa participante foi ocorrendo aos poucos e, até o momento em que acompanhamos esse grupo, os professores começavam a aderir à pesquisa, por compreender o seu papel formativo, assim como o seu papel de divulgação do trabalho realizado na escola.

A pesquisa participante foi um modelo de interação, cujas finalidades foram sendo traçadas pelos agentes do PGP, em termos dos interesses de pesquisa de cada agente. Mas a novidade em relação ao referencial teórico discutido foi a inserção desse tipo de pesquisa na associação livre e mediada pela ação comunicativa. Dessa junção resultaram relações entre os agentes da universidade e da escola que foram homogêneas. Esse resultado responde de modo argumentado ao principal "medo" dos proponentes da pesquisa participante, o de que não consigamos, de maneira alguma, ultrapassar as diferenças que se colocam entre pesquisador e comunidade de pesquisados. 
Além disso, tanto as pesquisas como as propostas de sequências didáticas realizadas pelos professores constituíram elementos que caracterizaram o cultivo das personalidades individuais desses atores, mesmo na interação. Essa situação já era prevista por Habermas como um dos fins da ação comunicativa.

Mesmo que esses agentes representem a pequena parcela da esfera escolar que se dispõe a dedicar tempo e esforço para as discussões dessas questões, é sempre importante relacionar a formação de professores com os discursos da possibilidade, da impossibilidade e das tensões. De modo que a falta de vontade política, os imperativos burocráticos aos professores e o isolamento deles não irão desaparecer da escola imediatamente, mas podemos criar essas associações que visam às possibilidades provenientes da liberdade de criação dos professores.

Porisso, não podemos estagnar as pesquisas que visam interpretar as relações entre universidade e escola, mas sim problematizar sempre os métodos com todos os envolvidos, como pôde ser observado na constante ação normativa do PGP. Ou seja, todo processo de interação que se propõe formativo e investigativo deve passar por momentos de problematização, agir comunicativo e consenso, ou a universidade não se aproximará dos ideais de igualdade com os professores da escola.

Ressaltamos que esses aspectos das associações livres somente são possíveis na escola pública, que possui o potencial de autorregulação e manutenção das esferas públicas. Essa proposição também foi relatada por Gomes (2007, p. 59-60), de modo que "Habermas diria que a escola deveria ser efetivamente um espaço público de acesso ao saber, capaz de interagir comunicativamente com os diversos setores que compõem a estrutura de uma sociedade". E isso foi o que pudemos observar, pois o setor privado de educação pode entender ações nas associações livres como um perigo às suas estruturas sistêmicas, de modo a coibir essas representações.

Além disso, sugerimos a continuidade das discussões sobre a pesquisa participante, na qual todas as etapas das pesquisas são acertadas com os agentes que constituem o grupo. Essa situação representou a confiança e a igualdade entre os professores, no sentido de que houve o reconhecimento do trabalho intersubjetivo e a consciência de grupo, em que todos os envolvidos são considerados internos. Portanto, podemos afirmar que a ação comunicativa e a constituição de associações livres, na qual interagem professores de diversas instituições, têm sido importantes para que esses grupos se mantenham ativos e preocupados com a formação contínua de professores. Situação incomum aos cursos de formação isolados nos quais não há continuidade alguma. 


\section{REFERÊNCIAS}

ALVES, J. A. P. A formação inicial de professores de Física e a construção de uma identidade. 2010. 233 f. Tese (Doutorado em Educação para a Ciência) - Faculdade de Ciências, Universidade Estadual Paulista Bauru, 2010.

ARAÚJO, I. L. A teoria da ação comunicativa de J. Habermas. Fundació Cátedra Iberoamericana: Universitat de las Illes Belears, 2004. Disponível em: <http:/ fci.uib.es/ Servicios/libros/veracruz/ines/>. Acesso em 11 jan. 2012.

BARDIN, L. Análise de conteúdo. São Paulo: Ed. 70, 1977.

CHAPANI, D. T. Políticas públicas e história de formação de professores de ciências: uma análise a partir da teoria social de Habermas. 2010. 421 f. Tese (Doutorado em Educação para a Ciência) - Faculdade de Ciências, Universidade Estadual Paulista Bauru, 2010.

CONTRERAS, J. A autonomia de professores. Tradução de Sandra Trabucco Valenzuela. São Paulo: Cortez, 2002.

DINIZ-PEREIRA, J. E. As licenciaturas e as novas políticas educacionais para a formação docente. Educação \& Sociedade, Campinas, v. 20, n. 68, p. 109-125, 1999.

ESTRELA, M. T. Profissão Docente: dimensões afectivas e éticas. Portugal: Areal Editores, 2010.

GAJARDO, M. Pesquisa Participante na América Latina. Tradução de Tânia Pellegrini. São Paulo: Brasiliense, 1986.

GIROUX, H. A. Os professores como intelectuais: rumo a uma pedagogia crítica da aprendizagem. Porto Alegre: Artes Médicas, 1997.

GOMES, L. R. Educação e consenso em Habermas. Campinas: Alínea, 2007. 160 p.

HABERMAS, J. A ideia de universidade: processos de aprendizagem. Revista brasileira de estudos pedagógicos, Brasília, v. 74, n. 176, p. 111-130, 1976.

HABERMAS, J. Mudança estrutural na esfera pública. Tradução de Fábio R. Kothe. Rio de Janeiro: Tempo Brasileiro, 1984.

HABERMAS, J. Teoria de la acción comunicativa, II: crítica de la razón funcionalista. Madrid: Taurus Humanidades, 1987, 618 p.

HABERMAS, J. Consciência moral e agir comunicativo. Tradução de Guido A. de Almeida. Rio de Janeiro: Tempo Brasileiro, 1989.

HABERMAS, J. Racionalidade e comunicação. Tradução de Paulo Rodrigues. Lisboa: Edições 70, 1996.

HABERMAS, J. Teoria do agir comunicativo: Racionalidade da ação e racionalização social. Tradução de Paulo Astor Soethe. São Paulo: Martins Fontes, 2012. v. 1.

HUBERMANN, M. O ciclo de vida profissional dos professores. In: NÒVOA, Antônio (Org.) Vidas de professores. Portugal: Porto Editora, 1992, p. 31-61.

KEMMIS, S. La formación del profesor y la creación y extensión de comunidades críticas de profesores. Investigación en la escuela, Sevilla, v. 8, n. 19, p. 15-38, 1993.

MIZUKAMI, M. G. N. A pesquisa sobre formação de professores: metodologias alternativas. In: BARBOSA, R. L. Formação de educadores: desafios e perspectivas. São Paulo: Editora Unesp, 2003, p. 201-232.

ORQUIZA-DE-CARVALHO, L. M. A educação de professores como formação cultural: a constituição de um espaço de formação na interface entre a universidade e a escola. 2005. 263 f. Tese (Livre Docência na disciplina de metodologia em ensino de Física) - Faculdade de Engenharia de Ilha Solteira, Unesp, Ilha Solteira, 2005. 
ORQUIZA-DE-CARVALHO, L. M. et al. Possibilidade de ação comunicativa na formação de professores de ciências e matemática. In: ENCONTRO NACIONAL DE PESQUISADORES EM ENSINO DE CIÊNCIAS - ENPEC, 7., 2009, Florianópolis. Atas... Florianópolis, 2009, p. 1-12. Disponível em: <posgrad.fae.ufmg.br/posgrad/ viienpec/pdfs/1611.pdf>. Acesso em: 16 jan. 2013.

PRESTES, N. Educação e Racionalidade: conexões e possibilidades de uma razão comunicativa na escola. Porto Alegre: EdiPUCRS, 1996.

\section{NOTAS}

${ }^{1}$ As descrições aqui realizadas se referem ao período de constituição de dados para a pesquisa, que corresponde, principalmente ao ano de 2012.

${ }^{2}$ Trabalhos de Conclusão de Curso, que no curso de licenciatura em Física de Ilha Solteira são, obrigatoriamente, sobre educação em ciências. Esses trabalhos são defendidos anualmente, perante uma banca de professores da universidade, nos Encontros de Prática de Ensino de Ilha Solteira Enpefis.

${ }^{3}$ Hora de Trabalho Pedagógico Coletivo. Comunicado Cenp (Coordenadoria de Estudos e Normas Pedagógicas), de 6 de fevereiro de 2009. Estipula 60 minutos semanais de discussões coletivas, de professores e gestores nas escolas. Atualmente, foi substituído pelas ATPC Atividades de Trabalho Pedagógico Coletivo.

${ }^{4}$ Do curso de Pós-graduação em Educação para a Ciência, da Faculdade de Ciências, Unesp campus Bauru.

Submetido: $15 / 06 / 2016$

Aprovado: 05/09/2016

Contato:

Nataly Carvalho Lopes

Departamento de Ciências da Natureza, Matemática e Educação, Centro de Ciências Agrárias, UFSCar - Campus Araras Rodovia Anhanguera, KM 174 Araras $|\mathrm{SP}|$ Brasil CEP 13.600-970 